\title{
CiENCIA, TECNOLOGÍA Y ESTADO MODERNO: ELEMENTOS DE LA BIOPOLÍTICA POTENCIALIZADORES DEL RACISMO
}

\section{LETICIA SARMIENTO SARMIENTO ${ }^{1}$}

RESUMEN: El racismo es una de las categorías que permiten entender diversas cuestiones en torno a la violencia social. Su utilidad radica en que puede explicar el exterminio de minorías, la exclusión social, la estratificación, la poca asimilación de los inmigrantes, los feminicidios, delitos cibernéticos, el secuestro, el fenómeno de linchamientos o la presencia de héroes anónimos. La segregación moderna aunada con la ciencia y tecnología, se desarrolla de manera paralela al advenimiento y establecimiento del Estado Moderno que se sustenta en sus aparatos de control e ideológicos en sincronía con el discurso político del capitalismo, denominado Biopolítica.

Palabras clave: Biopolitica, Estado Moderno, Ciencia, Racismo, Tecnología, Mecanismos de regulación, Dispositivos de seguridad.

ABSTRACT: Racism is one of the categories that allow us to understand various issues related to social violence. Its usefulness lies in the fact that it can explain the extermination of minorities, social exclusion, stratification, the little assimilation of immigrants, femicides, cyber crimes, kidnapping, the phenomenon of lynchings or the presence of anonymous heroes. The modern segregation combined with science and technology, is developed in parallel to the advent and establishment of the modern state that is based on devices of control and ideologies in sync with the political discourse of capitalism, called Biopolitics.

Keywords: Racismo, Biopolítica, Política Criminal, criminal, criminalización, Estado, Derecho, Ciencia, Tecnología, Positivismo, Evolucionismo social.

1 Maestra en Política Criminal y Licenciada en Sociología por la Universidad Nacional Autónoma de México, Facultad de Estudios Superiores- Acatlán. 
SUMARIO: I. Nota introductoria. II. Ciencia y tecnología de la biopolítica. III. Enmascaramiento del racismo como capitalización del Estado Moderno. IV. Bibliografía

\section{NOTA INTRODUCTORIA}

71 racismo es un fenómeno paralelo al Estado Moderno y al capitalismo, obedece a mecanismos fronterizos de división ideológica que define la conducta y el tránsito poblacional encaminados el predominio del Estado como centro de organización racional, bajo lineamientos jurídicos y tecnológicos devenidos de paradigmas científicos como el positivismo y el evolucionismo social. Se exacerba cuando surgen mecanismos de regulación que apelan al resguardo y libertad de la soberanía del Estado racional.

La soberanía apela a la racionalización de la intervención preventiva Estatal Moderna en los factores de riesgo bajo hipótesis de discursos científicos; pero, además, dichas intervenciones, denominadas políticas públicas de gobierno, se legitiman en la retórica argumentativa e intervención racional del Derecho, con el fin de conducir las conductas de la población de un Estado Soberano ubicado geográficamente por fronteras, lineamientos racionales progresistas y científicos de la gobernabilidad.

El racismo biológico constituye un episodio precedente al marco que lleva a gobernar a las personas considerándolas como "población”, es decir, entendiéndolas a partir de los procesos vitales que las conforman, según los postulados racionales- científicos: natalidad, fecundidad, mortalidad, salud, morbilidad, sexualidad, medio ambiente, vivienda, alimentación y un largo etcétera. Es decir, la gobernabilidad apela a modos técnicos de organizar o de problematizar el mundo. Éstos pueden encontrarse funcionando en las teorías filosóficas o en la argumentación teológica, pero también en la planificación urbana, las prácticas de contabilidad, los recursos estadísticos, la crianza de los niños, la cartografía militar, el diseño 
arquitectónico o campañas militares, sin embargo este trabajo se enfoca a la cuestión criminal.

11. Ciencia y tecnología de la biopolítica

Será el reino de la inteligencia científica, el más arrogante y despectivo de todos los regímenes.

BAKUNIN

\section{Discurso Científico}

Con el advenimiento de la modernidad, la potestad Política deja de ser "un arte exclusivo de príncipes" porque se populariza, a partir de entonces, el nuevo modo de conocer (episteme) llamado método científico, da la pauta a la estructura de la Ciencia Política como disciplina de conocimiento y análisis que se desarrollará, al igual que los constructos de soberanía y gobernabilidad tan imprescindibles para la organización social del EstadoModerno.

Los fundamentos teóricos de la Ciencia Política se retroalimentan de la herencia filosófica de pensadores ilustrados como Maquiavelo, Bodin, Hobbes, Montesquieu, Rosseau, Toqueville, por mencionar algunos. Pero el cogito ergo sum de Descartes (1596-1650) fue el elemento imprescindible para el nuevo modo de conocimiento (Episteme) que se sostendrá, a partir de entonces, en los criterios del método científico gestado en la obra El discurso del Método de 1637. La nueva Episteme acompaña a los postulados filosófico-políticos de estos personajes para que se conviertan en el paradigma político de gobierno del Estado Moderno que apela a la racionalidad, al sufragio universal, a los derechos del hombre, libertad, igualdad, propiedad, a la soberanía y a la Democracia.

Actualmente, las ciencias sociales tienen sus paradigmas científicos independientes entres ellas, e independientes de las ciencias exactas, pero en los albores del método científico, las ciencias exactas fueron pioneras en cuanto a la exploración, explicación y apli- 
cación en necesidades humanas. Algunas ciencias primigeneas en la carrera científica moderna fueron la astronomía, principalmente por los intereses en cartografía de los inversionistas en exploraciones de nuevos territorios, la física con sus aplicaciones tecnológicas en diversas áreas como el caso de la máquina de vapor, y la medicina que siempre es útil, por mencionar algunos ejemplos de ciencias experimentales que encontraron acomodo y atención de los científicos. Todo esto derivó, como es sabido, en la revolución industrial a partir de la segunda mitad del siglo XVIII, coyuntura histórica que generó una transformación en la sociedad, mayor división de trabajo, migración masiva de las poblaciones del campo a la ciudad, indigencia, hacinamiento en las urbes y el desempleo.

Por su parte la Episteme Biológica, debido a un cúmulo de argumentos de la época, logró el caudal teórico tan influyente del Evolucionismo Darwiniano, ${ }^{2}$ cuyo respaldo se sustenta en las discusiones e investigaciones previas y contemporáneas a la vida de Carlos Darwin (1809-1882) como lo demuestran los aportes de Lamarck y de Wallace entre otros cofundadores y continuadores de esta visión como lo fue más adelante Gregorio Mendel.

Cabe destacar que de manera paralela, Augusto Comte (17981857), tratando de emular el método de las ciencias exactas para cimentar el método de la ciencia social, logra exponer El Positivismo en su obra La filosofia positiva ${ }^{3}$ donde postula la ley de los tres estadios: teológico, metafísico y positivo (o científico); además de una serie de argumentos que han sido objeto de cuestionamientos en torno a su viabilidad científica. Ya que Comte propone al positivismo como método científico para resolver las cuestiones de la sociología, así llamada por él, como ciencia encargada de resolver los problemas sociales debido a que las ciencias exactas eran inviables para afrontar o entender los procesos sociales del momento,

2 Cfr., Charles Darwin, El origen de las especies, 6 ed., México, Porrúa, 1997.

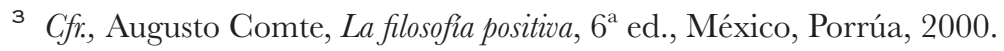


como lo fue la revolución francesa o la incipiente sociedad industrial deEuropa.

Mientras el biologismo trata de entender la vida mediante la adaptabilidad de los organismos en la búsqueda de la supervivencia para la perpetuidad de las especies y su variabilidad, el positivismo es la visión de etapas superpuestas y superadas; el estadio teológico dice ser la etapa de la humanidad primitiva que pasará a una especie de adolescencia o metamorfosis llamada metafísica indispensable de atravesar y superar para pasar al eslabón, según Comte, más avanzado de la humanidad, el estadio científico, éste es aquel que desarrollan las civilizaciones más avanzadas, según la lógica progresista delpositivismo.

Hasta aquí podemos decir que la visión progresista en diversas Epistemes científicas es paralela, ya sea a partir del origen de la sociología conocida como positivismo o en el argumento biológico conocido como evolucionismo, tendrán una reiteración predominante en otros ámbitos como en la ciencia política. Precisamente en la buena fe, en la intención de mejorar la vida y de resolver los problemas y conflictos sociales o en la búsqueda de enfrentar toda situación emergente, la ciencia genera diversos mecanismos y técnicas experimentales para poder encauzar diversos fenómenos: físicos, ambientales, psíquicos y médicos.

El progreso tecnológico a partir de la primera revolución industrial, será sinónimo de desarrollo social, idea progresista derivada del evolucionismo social derivada del positivismo y retroalimentada por el estructural funcionalismo, cuyo argumento radica en asimilar a la sociedad como un organismo vivo que evoluciona por el progreso, entendido éste como la producción tecnológica masiva aplicada y potencializada, principalmente, en las grandes urbes como fue la incipiente sociedad industrial de Inglaterra.

Bajo el método científico histórico-positivista se explica el proceso histórico como un avance progresivo y lineal, hacia un dominio total del hombre sobre la naturaleza, por medio de avances cien- 
tíficos y tecnológicos donde se mira la idea de un futuro resuelto, fuera de conflicto porque la técnica científica se aplica bajo una certidumbre legitimada en la potenciación de la vida militarizada, tecnificada, industrializada y posteriormente robotizada para $\mathrm{cu}-$ brir las necesidades, resolver las demandas humanas y conflictos propios de la dinámica social. Es en la categoría de sociedad del progreso donde se fija la certidumbre y confianza en el método científico y sus aplicaciones tecnológicas, en todos los ámbitos, para el desarrollo "idóneo" de una sociedad.

La categoría de progreso y desarrollo se entienden como sinónimos, donde las civilizaciones, altamente industrializadas utilizan este discurso en el ámbito político para justificar su dominio legitimado bajo el argumento de superioridad organizacional por su poderío tecnológico y científico en oposición al etiquetamiento estigmatizador de inferioridad industrial como sinónimo de escases en desarrollo y progreso, y por lo tanto, incivilizada. En un contexto donde la pobreza se entiende como falta de tecnología industrial, comienza a ser un significante despectivo y negativo, pero sobre todo, anómalo, criminógeno, causante de conductas desviadas cuya etiqueta es de origen científico mediante el argumento histórico-positivista.

Cuando las anteriores etiquetas de estigmatización permiten la clasificación de grandes conglomerados humanos pertenecientes a poblaciones no industrializadas, la colonización de las capitales industriales expanden su poderío, no sólo por su supremacía militar, sino por su intervención legítima sustentada en la ideología de superioridad evolutiva heredada por el darwinismo social, adaptación de la teoría de Darwin por la teoría social moderna incipiente, para la clasificación de razas basada en un método antropométrico que utiliza la fisionomía biología de los hombres de diversosorígenes.

En este sentido, la variabilidad genética y la diversidad bilógica que aborda la antropología física, en sus inicios, sostiene la categorización científica en razas inferiores, (en la actualidad se denominan etiquetas estigmatizantes), porque se logra una clasificación susten- 
tada en elementos físico-biológicos de nocividad que argumenta la evolución social desde lo físico-biológico. Las características físicas diversas de los occidentales, se denominan como patológicas, nocivas socialmente e involucionadas, según el argumento médico (principalmente por argumentos como el de Lombroso), por poseer las características biológicas innecesarias que requiere el ser humano para evolucionar, partiendo de la idea de que el hombre blanco es superior, es decir, la incapacidad biológica de abandonar las características primitivas y de barbarie corresponden, "hipotéticamente", a las características físicas de los hombres nooccidentales.

Aunque la idea de evolución se afianzó con la teoría de Darwin condensada en su libro El origen de las especies, cuyo método radicó en la observación multidisciplinaria y en diversos elementos, geológicos, de latitud, altitud, temperatura, genética, etcétera, argumenta sobre la evolución desde otra perspectiva muy diferente al darwinismo social, nunca antepone estadios de superioridad, simplemente argumenta sobre adaptabilidad a las condiciones cambiantes del medio ambiente, pero como fenómeno que no tiene que ver con la visión histórica del positivismo lineal y progresivo, es un proceso de creación y herencia de vida universal, interconectada como una cadena trófica codependiente de cada eslabón en correspondencia con de los demás para la perpetuidad de la vida que requiere la mayor variabilidad. ${ }^{4}$

Por otro lado, cabe mencionar que la guerra o la violencia son a históricas, es decir no corresponden a un estadio de la sociedad, pues la violencia no tiene parámetros homologados de medición, ni ausencia en ninguna sociedad y por lo tanto la barbarie no es un elemento de incivilización sino de clasificación del otro, de lo diferente, o como actualmente se le nombra: es un constructo social de discriminación.

4 Cfr., Charles Darwin, op. cit., nota 1. 
Términos como incivilizado, salvaje, involutivo o barbarie obedecen a una clasificación, que se podría decir, son la muestra constante de lo que en el siglo XX se denominó racismo, con la misma función de exclusión social, pero, elaboradas desde otros contextos. Por ejemplo, la noción de barbarie se dirige hacia lo diferente del otro, hacia la cosmovisión que una sociedad se ve imposibilitada para asimilar por desconocido e incomunicable, donde el otro significa oposición, peligro a lo establecido de lo ya conocido.

Tzvetan Todorov hace un recorrido, etimológico e histórico, de cómo el significado de barbarie es utilizado para dirigirse a lo ajeno en sentido despectivo, porque los rasgos del otro no asimilado se perciben como ofensivos y para dirigirse a su ser se le nombra, agresivo, violento, incivilizado: bárbaro.

La barbarie es resultado de un rasgo del ser humano del que parece ilusorio esperar que algún día llegue a erradicarse definitivamente. Así para nosotros no corresponderá a ningún periodo concreto de la historia de la humanidad, ni antiguo, ni moderno, a ninguna de las poblaciones que cubren la superficie de la tierra. Está tanto en nosotros como en los otros. Ningún pueblo ni individuo está inmunizado contra la posibilidad de llevar a cabo acciones bárbaras. El hombre prehistórico que mata al vecino de la cueva de al lado, Caín asesinando a Abel, el tirano contemporáneo que tortura a sus adversarios, todos participan de la misma pulsión bárbara, la de un sentimiento de rivalidad asesina que hace que neguemos a los demás el derecho a acceder a las mismas ventajas y a los mismos bienes de los que quisiéramos disfrutarnosotros. ${ }^{5}$

Fenómenos violentos como la guerra, linchamientos, homicidios, parricidios, suicidios se encuentran en toda forma de organización social. Dice Durkheim que el delito es normal, como dichos fenómenos, el problema es cuando su presencia es muy frecuente, entonces

5 Tzvetan Todorov, El miedo a los bárbaros, trad., Noemí Sobregués, México, Círculo de lectores, 2013, p. 38. 
las llama patologías sociales. Podemos decir que estos son fenómenos constantes de las dinámicas sociales y su escaza o reiterada presencia depende del grado de cohesión social. Por ejemplo, en el caso de la Guerra, Pierre Clastres, en su obra Arqueología de la violencia: la guerra en las sociedades primitivas, demuestra, basándose en hechos etnográficos, que la sociedad primitiva tiene un carácter estructural y político de la actividad bélica. Analiza la restringida autoridad del jefe, limitada a hablar en nombre de una ley ancestral inalterable. Estudia el papel de los enemigos y de las alianzas. Explica el estado de guerra permanente y su lógica centrífuga de dispersión. Revela por qué la comunidad primitiva, conservadora, homogénea e independiente, renuente a cualquier tipo de división social y de acumulación de poder, es una sociedad para la guerra y en contra del Estado. Entonces podemos decir que la cohesión social es la primacía de la conservación de la comunidad sin estratificación, en la medida en que se antepone la guerra por la independencia política. La guerra de la comunidad primitiva que aquí entendemos como comunidad primigenia, por su instinto de conservación solidaria sustentado en el uso permanente de guerra y comercio forjado en la alianzas como recursos de subversión constante y paradójicamente recursos deconservación. ${ }^{6}$

Lo importante no son los diversos matices de la violencia que son constantes en las dinámicas de las sociedades, lo importante son los artificios sociales que ingenia cada civilización para producir cultura a partir de dicha constante, es decir, la cultura crea mecanismos de interacción social para contener la violencia en potencia. Es decir, es de suma importancia, cómo se establecen mecanismos sociales de identidad para el ejercicio del poder que es el principio de la identidad política y de la instauración perpetua de lapaz.

6 Cfr., Pierre Clastres, Arqueología de la violencia: la guerra en las sociedades primitivas, $2^{\mathrm{a}}$ ed., trad. Luciano Padilla López, México, FGE, 2009. 
En la modernidad, la ciencia se ha implicado más en la clasificación de diversos matices de violencia, de incertidumbre, de inseguridad desde diversos ámbitos de seguridad comomateria ambiental, debiotecnología, de salud, por mencionar ejemplos, analizándolos como situaciones de riesgo para manipularlas mediante la aplicación técnica de dispositivos de control científico; mientras la contemplación de lo simbólico, para la construcción de la autonomía política para la toma de decisiones, derivado de la dinámica cultural, ha pasado a un plano relegado por la inmediatez de la tecnificación que propone al individuo resolver sus problemas.

Es decir, la solidaridad comunitaria se ve transgredida por lo tecnológico al colocar la seguridad del individuo como centro del universo científico, segregándolo y excluyéndolo del principio de lo social, del otro, de los otros, de la comunidad. Es justo aquí donde encontramos mayor desconfianza del individuo hacia los otros, porque se encuentra aislado de la comunidad, propiciando el racismoexacerbado.

Según Geulen, el término raza tiene que ver mucho más con el uso lingüístico corriente y el político que con el científico:

La palabra raza, derivada etimológicamente del árabe raz (cabeza, jefe y también origen) y del latín radix (raíz), en la época de su aparición de una forma amplia, en el siglo XV, se usa sobre todo en dos contextos: en la descripción de poderosas familias nobles o dinastías dominantes, y en la cría caballar. En ambos casos, raza era el término general que se aplicaba a las características que distinguían la nobleza, importancia e ilustre linaje de una familia concreta, así como de los caballos de raza.

En la España de la Reconquista se empleó por primera vez este término en relación con los judíos, para diferenciar así a grupos humanos que ya no se distinguían del pueblo llano por su linaje noble, sino que se diferenciaban horizontalmente y por aspectos relacionados con la religión, la cultura y su origen. Pero no fue 
hasta finales del siglo XVIII cuando el término raza se convirtió en sentido estricto en una categoría de la historia natural. ${ }^{7}$

Asimismo, Geulen, argumenta que el culto a la ciencia, a la tecnología y el progreso potencializan al racismo:

[...]El siglo XX es la época en que la ciencia moderna se ha implicado más ampliamente con la ideología del racismo, la ha recreado en parte y ha participado también en su transformación práctica. Esto se debió, por un lado, a un cambio en la propia imagen de los científicos que, a la vista de la aplicación técnica que muchos de sus conocimientos habían tenido ya en el siglo XIX, se vieron a principios del XX cada vez más orientados a la práctica, y con la ayuda de la tecnología se sintieron llamados a la mejora del mundo de forma notable. Por otra parte, se debió también a la política que, a partir del cambio de siglo, se puso en práctica en casi todos los Estados modernos con el fin de aspirar a una especie de ideal de eficacia y racionalidad científica. Ya fuera en el ámbito social, en el financiero y económico, en la política exterior imperialista, cada vez más importante, o en el terreno sociológico y demográfico, en todas partes se dio una orientación más o menos científica a las decisiones políticas. En general, esta actitud se consideraba una consecuencia de un proceso de racionalización, pero suponía en realidad una limitación del ámbito de lo político y de la voluntad democrática. ${ }^{8}$

Entonces, lo que nos interesa es cómo ese Darwinismo social tiene injerencia en los monumentos conceptuales de la tradición filosófica y científica, principalmente a través del positivismo, que contribuyen a fortalecer y dar continuidad al discurso científico y a la aplicación técnica del racismo legitimado en la soberanía del Estado moderno para el progreso, precisamente porque toman mayor fuerzaideológica.

7 Christian Geulen, Breve historia del racismo, trad. Elena Bombín Izquierdo y Jesús de la Hera Martínez, Madrid, Alianza, 2007, p. 18.

8 Ibidem, p. 135. 
En el racismo de la eugenesia del siglo $\mathrm{XX}$, en un contexto geopolítico de una fase histórica, altamente capitalista, donde el control, la seguridad, la prevención y la buena fe en la ciencia explotan el exterminio, la extirpación, la eliminación y la prevención de lo nocivo en pro del progreso, de la seguridad, de una vida más longeva y certera del individuo, invirtiendo en la prevención del riesgo, control de la incertidumbre y en la eficiencia de la seguridad. Justificación que promete certeza en el futuro a través de los argumentos de los diversos modelos científicos y tecnológicos que se desarrollan exponencialmente.

\section{TeCnificación de La CIEnCia de la gobernabilidad}

Es en este proceso histórico de la modernidad donde podemos rastrear diversas políticas de exterminio a lo largo del planeta. Territorios habitados por poblaciones de tribus nativas sometidas, explotadas, esclavizadas y exterminadas por su incompetente capacidad militar en materia de aplicación técnica armamentista. En este sentido podemos hablar de un ejemplo, la supremacía militar del europeo, durante el siglo XVI, por la aplicación que le dio a la pólvora con la invención y perfeccionamiento del arma de fuego; sin olvidar su dominio marítimo en cuestión militar y comercial.

Estos fenómenos de conquista y colonización no son nuevos, en la historia encontramos diversos procesos de dominación y hegemonía que se dan como procesos de aculturación de una civilización a otras; pero lo que es propio del contexto moderno, es la capitalización que potencializa y legitima el proceso contextual del llamado Estado Moderno del progreso, donde la soberanía de supedita a un emblema de seguridad delimitando los nuevos factores políticos para delinear fronteras de ordenamientos en diversos ámbitos sociales, pero primordialmente poblacionales, pues a partir de entonces, la soberanía encauzará, 
lo ahora denominado como gobierno. En este sentido, no sólo se define al territorio bajo límites, divisiones o fronteras políticas, sino también, sobre poblaciones, lo que respaldará y sustentará el poderío de gobernabilidad que es llamadobiopolítica.

Esta última concurre a los discursos científicos con aplicación técnica para ciertos fines de gobernabilidad, por ejemplo, de las matemáticas se usan los estudios estadísticos y proyecciones probabilísticas para dar simulaciones de certeza en los censos poblacionales, en materia de políticas públicas de población. Pero la dominación ya no será impuesta, sino negociada desde la libertad soberana, no para el individuo, sino para el fin de la población que es su perpetuidad, el culto narcisista a la salud y a la belleza, y la garantía de seguridad entendida comoresguardo.

La biopolítica, para Francisco Vázquez es una herramienta, de análisis para dar cuenta de procesos masivos que acompañan a la globalización económica:

En nuestras sociedades el racismo étnico y la xenofobia constituyen sólo un aspecto sectorial de un fenómeno mucho más vasto: el racismo biológico. Éste consiste en la acción colectiva (control, estigmatización, deportación, exterminio, y un largo etcétera) sobre los seres humanos identificándolos y agrupándolos a partir de características que poseen en cuanto seres vivos. A su vez, el racismo biológico constituye un episodio inscrito en un marco mucho mayor: el que lleva a gobernar a las personas considerándolas como población, esto es, entendiéndolas a partir de los procesos vitales que las conforman (natalidad, fecundidad, mortalidad, salud y morbilidad, sexualidad, medio ambiente, vivienda, etcétera). A este gobierno le denominamos con el nombre debiopolítica. ${ }^{9}$

Aunque la denominación biopolítica se remonta a 1905, cuando la utiliza por primera vez el teórico sueco Rudolf Kjellen en el contexto de una concepción organicista y racista del Estado, estamos de

9 Francisco Vázquez García, La invención del racismo. Nacimiento de la biopolítica en España, 1600-1940, Madrid, Akal, 2009, p. 6. 
acuerdo con Francisco Vázquez García, al reconocer que Focault acuña el concepto teniendo en cuenta un trasfondo de literatura política y antropológica que, desde comienzos del siglo XX hasta los años setenta, utilizaba profusamente; cabe mencionar que esto es reconocido por Roberto Esposito en su obra Confines de lo político. ${ }^{10}$

En este sentido la biopolítica es una herramienta de análisis, en conjunción con la ciencia política paralela o a otras disciplinas, cuyo objetivo es gobernar a las personas desde la categoría de población, desde sus procesos para lograr los fines que se delinean desde la planificación y estrategias de políticas públicas, orquestadas mediante técnicas aplicadas que materializan los objetivos discursivos de lo políticamente correcto determinado por el gobernador en turno, para enfrentar aquellos problemas que una sociedad demanda ser definidos y delineados desde la intervención gubernamental materializada en técnicas aplicadas desde la ciencia. Por ejemplo, desde la cuestión de salubridad se definen necesidades, estrategias y técnicas que permiten la materialización de dicho dispositivo gubernamental, cuyo fin es brindar seguridad, certeza en materia social, poblacional y de salud; en este sentido, el caso de la aplicación de determinadas vacunas o medicamentos en los sectores poblacionales están regidos por una serie de discursos, científicos, tecnológicos y de logística biopolítica, que buscan un objetivo determinado, en determinado sector, en función de determinada soberanía, que obedece al contexto en concreto de una categoría de Estadodeterminado.

Para Francisco Vázquez García, la población es la protagonista de la biopolítica que es una herramienta de análisis resultante de un proceso genealógico en el campo de pensamiento, presentado en argumentos históricos con autores como Michel Focault, es este último personaje quien más ha destacado por sus aportes al darle la categoría de instrumento teórico.

10 Cfr., Roberto Esposito, Confines de lo político, Madrid, Trotta, 1996. 
La biopolítica sería entonces la conducción de las conductas relacionadas con el ser humano en tanto organismo viviente, implicado por ello en una serie de procesos vitales de alcance colectivo. Éste análisis se enfoca a procedimientos, modos técnicos de organizar o de problematizar el mundo. Éstos pueden encontrarse funcionando en las teorías filosóficas o en la argumentación teológica, pero también en la planificación urbana, las prácticas de contabilidad, los recursos estadísticos, la crianza de niños, la cartografía militar, el diseño arquitectónico o las campañassanitarias.

La historia de la racionalidad debe dilucidarse también en este ámbito de objetos y actividades, modestas si se les compara con los grandes monumentos conceptuales de la tradición filosófica y científica. ${ }^{11}$

Al igual que Focault, Francisco Vázquez propone el curso de la historia desde una perspectiva genealógica para explicar las diversas intervenciones que dan los Estados racionales o modernos ante lo denominado como lo social. Estado liberal, Estado benefactor o welfare, Estado liberal avanzado o neoliberal cuya intervención técnica obedece a pensamientos filosóficos desde el recurso de la historia: Historia del pensamiento económico y político, Historia de la estadística, Historia de la medicina y de las ciencias de la salud en general; Historia de la administración y de las instituciones, Historia de la educación, Historia del urbanismo y de la arquitectura; Historia cultural e Historia de la marginalidad;Historia del derecho;Historia de la teología. Todos estos elementos son indispensables para entender el proceso y situaciones coyunturales de un Estado laico, racional, o Moderno.

Las acciones programadas para inocular la viruela a una colectividad, organizar el enterramiento de cadáveres en una ciudad, censar a los vecinos, asentar una colonia agrícola, confeccionar tablas de nacimientos y defunciones o justificar la expulsión o la asimilación de una minoría disidente constituyen enclaves relevantes para la

11 Francisco Vázquez García, op. cit., nota 8, p. 5. 
historia de ese tipo de racionalidad que llamamos biopolítica y que presenta estilos o regímenes diferentes en el curso de la historia. ${ }^{12}$

En cuanto comienza a construirse la noción de soberanía, desde el pensamiento filosófico-político, se da cabida a una comunidad internacional legitimada en ordenamientos jurídicos multilaterales, donde la seguridad nacional apela a la integración de constructos soberanos paralelos entre Naciones-Estado para defender su territorio de las potenciales invasiones militares del estado latente de guerra que atenta con reducir o invadir las fronteras geopolíticas. Del mismo modo que de manera externa, el soberano (según el modelo de cada Estado) busca medios para su ordenamiento, de manera interna se van perfilando mecanismos de seguridad o reguladores de lo que se denomina, durante estos siglos, como lo social desde una anatomopolítica de los cuerpos y una biopolítica de las poblaciones.

Junto a los mecanismos disciplinarios que apuntan al organismo individual se advierte ya en la Europa de las luces la presencia de un tipo de poder que no encaja bien en el patrón de la guerra y que tampoco obedece bien al patrón del Derecho.

Se trata de tecnologías políticas que no se dirigen a la reforma del organismo individual, a su domesticación y potenciación utilitaria, sino que buscan regular los grandes procesos biológicos que afectan una población en su conjunto y que poseen su propia normatividad intrínseca (natalidad, morbilidad, vivienda, vejez, siniestrabilidad, etc.). Ciertos procedimientos, tales como las campañas para la vacunación infantil o la esterilización de débiles mentales, medidas fiscales para incentivar la natalidad, seguros sociales, políticas de vivienda y educativas para prevenir la delincuencia, etcétera, no pretender vencer la resistencia individual para ajustarla a un estándar, como sucedía en la normalización disciplinaria; operan mediante el cálculo de riesgos. No se trata, por ejemplo, de derrotar al crimen, ni de corregir a los criminales, para que se conviertan en buenos ciudadanos, sino de gestionar la tasa de criminalidad dentro de un

12 Ibidem, p. 6. 
intervalo aceptable, que no suponga una amenaza para el conjunto de población. ${ }^{13}$

En este proceso soberano se perfila hacia una acción del gobierno de conducir las conductas donde la acción del gobierno apunta a facilitar la capacidad de elección de los individuos sin anular su libertad, sino, coordinarla con las propias metas de la nación. El filósofo francés Focault entiende a la gobernabilidad como arte de gobierno y racionalidad del gobierno al igual que Francisco Vázquez: "Éste es un sistema de pensamiento acerca de la naturaleza y práctica del gobierno, de la conducción de las conductas (quién tiene que gobernar, cómo se entiende el gobernar mismo, qué o quiénes son los gobernados) dentro de las coordenadas históricasprecisas". ${ }^{14}$

Para Focault la gobernabilidad es el arte de gobernar, el gobierno se diferencia de la dominación porque no pretende anular la iniciativa de los gobernados, no impone un estándar (como el caso del encauzamiento de los cuerpos en el ejército) sino lo emplea a su favor. Primero busca el estándar o parámetro con la ciencia y luego lo aplica con la tecnología para el biopoder. El modelo de gobierno sirve para rendir cuentas que no son de oposición como en el ámbito bélico de dominación donde hay subversión o levantamiento en armas del pueblo, o, con la imagen cuerpo a cuerpo en un combate de guerra. En el modelo entendido como técnica, no como órgano del Estado, la acción o intervención del gobierno radica en la conducción de conductas, sin potencial de fuerzas, cuerpos físicos por dominar, su técnica no es militar, radica en la conducción de conductas.

\section{ENMASCARAMIENTO DEL RACISMO COMO CAPITALIZACIÓN DEL ESTADO MODERNO}

\footnotetext{
13 Ibidem, p. 10.

14 Ibidem, p. 12.
} 


\section{Consolidación del Estado moderno}

En los últimos siglos de la historia de la humanidad, el modelo de Estado preponderante que contribuyó al desarrollo del capitalismo, como lo conocemos actualmente, es el del Estado moderno, cuyo contexto coincide con la industrialización, tecnología científica y variadas revoluciones de organización social.

[...]El Estado moderno es una asociación de dominio de tipo institucional, que en el interior de un territorio ha tratado con éxito de monopolizar la coacción física legítima como instrumento de dominio, y reúne a dicho objeto los medios materiales de explotación en manos de sus directores pero habiendo expropiado para ello a todos los funcionarios de clase autónomos, que anteriormente disponían de aquellos por derecho propio, y colocándose así mismo, en lugar de ellos, en la cima suprema. ${ }^{15}$

Sus características son evidentes, están cargados de nacionalismo que delimita fronteras confrontadas, continuamente, con los demás Estados. El modelo de Estado moderno se define superior a otros modelos porque se forja en la ideología del positivismo. Este último ha desarrollado una demagogia sustentada en la promesa de la seguridad y del futuro certero en todas las esferas del ámbito cultural; el argumento se sustenta en la práctica de la industrialización, técnicas avanzadas aplicadas en todos los ámbitos de la vida dirigidas por el Estado, bajo el discurso de la técnica científica o filosofía positiva.

La filosofía positivista o, también conocida, como positivismo, fue el resultado de procesos industriales y científicos que logró condensarse en ideología política. Su máximo representante, quien logra exponer en su obra escrita todos estos acontecimientos sociales, como ya se mencionó antes, es el filósofo social Augusto Comte.

15 Max Weber, Economía y sociedad, México, $17^{\mathrm{a}}$ ed., trad. José Medina Echavarría et al., FCE, 2008, p. 1056. 
Este personaje estaba preocupado por revoluciones sociales como lo fue la revolución francesa que acarreaban crisis y subversiones con gran cambio cultural.

Comte consagraría su esfuerzo a concebir un modo de resolver el problema social bajo un nuevo método. Halló la respuesta en la ciencia, hacia la que estableció un verdadero culto: el conocimiento objetivo que proporciona la ciencia, éste último, debía aplicarse a la ordenación de los asuntos políticos, económicos y sociales, superando las ideologías apoyadas en la imaginación, los intereses o los sentimientos. ${ }^{16}$

En este contexto todo problema o incertidumbre social que acontece debe ser resuelto desde la razón de la ciencia, pero quien debe dar el visto bueno es el Estado desde su ordenamiento jurídico y desde su constructo de seguridad: seguridad social, seguridad sanitaria, seguridad demográfica, seguridad educativa, seguridad alimentaria, seguridad laboral, seguridad nacional, seguridad pública, etcétera, porque se considera al Estado como vector y gestor para cubrir las necesidades sociales debido a su carácter soberano. Una de sus herramientas es la industria y su gran cortesana: la ciencia con tecnología. En este sentido la soberanía es el hilo conductor del Estado ya que, soberano, es quien tiene el poder de decisión política.

El término soberanía tiene sus orígenes con Jean Bodin desde el siglo XVI. Según la clásica definición de Jean Bodin, recogida en su obra de 1576 Los seis libros de la República, soberanía es el poder absoluto y perpetuo de una República; y soberano es quien tiene el poder de decisión, de dar las leyes sin recibirlas de otro, es decir, aquel que no está sujeto a leyes escritas, pero sí a la ley divina o natural. ${ }^{17}$

\footnotetext{
16 Cfr., Augusto Comte, op. cit., nota 2.

17 Cfr., Jean Bodin, Los seis libros de la República, Madrid, Tecnos, 2006.
} 
Esta inicial definición muestra en síntesis la amplitud del concepto de soberanía, que, como tal, viene perdurando a través de los tiempos, aunque no exento de variaciones a lo largo de la historia en su intento de justificar el devenir del sujeto de la soberanía (el Pueblo, la Nación, el Estado).

Thomas Hobbes suprimió la dependencia de la ley natural que Jean Bodin trazaba en su definición de soberanía y constituyó al soberano en única forma de poder. De este modo, en su tratado más famoso, Leviatán, publicado en 1651, justifica filosóficamente la existencia del autoritarismo estatal. Si bien habría que precisar que la Ley Natural no es ajena a las teorías de Hobbes. Dice éste:

[...] La Ley de la naturaleza y la ley civil se contienen una a otra, y son de igual extensión [...] Las leyes de la naturaleza, que consisten en la equidad, la justicia, la gratitud y otras virtudes morales que dependen de ellas, en la condición de mera naturaleza no son propiamente leyes, sino cualidades que disponen los hombres a la paz y la obediencia.

Tras estas reflexiones, concluye Hobbes que:

[...]la ley de la naturaleza es una parte de la ley civil en todos los Estados del mundo [...] Cada súbdito en un Estado ha estipulado su obediencia a la ley civil; por tanto, la obediencia a la ley civil es parte, también, de la ley de la naturaleza. La ley civil y ley natural no son especies diferentes, sino parte distintas de la ley; de ellas, una parte es escrita, y se llama civil; la otra no escrita, y se denomina natural. ${ }^{18}$

Los conceptos de Hobbes como el pacto social y la noción de seguridad contribuyen como soportes de la teoría del Estado soberano. Aunque no es el único filósofo que ha dado esta clase de aportes, sus argumentos han influido y desencadenado una serie de

18 Tomas Hobbes, Leviatan, 2ª ed., trad. Ana Stellino, México, Gernika, 2000, t. I, p. 160 . 
cimientos que han solidificado el argumento racional del Estado para que predomine como organización social.

En su tratado más famoso, Leviatán (1651), Hobbes señaló que en el estado de naturaleza todos los hombres son libres, y sin embargo viven en el perpetuo peligro de que acontezca una guerra de todos contra todos (bellum erga omnes). Desde el momento en que la sumisión por contrato de un pueblo al dominio de un soberano abre una posibilidad de paz, el principio de autoridad (en tanto que sea garante de la paz) constituye el fundamento del Derecho.

Partiendo de la definición de hombre y de sus características, Hobbes, explica la aparición del Estado y de los distintos tipos de gobierno que son necesarios para la convivencia en sociedad. El origen del Estado es el pacto que realizan todos los hombres entre sí, subordinándose desde ese momento a un gobernante, el cual procura por el bien de todos los súbditos y de él mismo. De esa forma se conforma la organización social.

El pacto social es un constructo que tiene una ilación muy interesante y convincente que vale la pena analizar. Hobbes plantea que el pacto social se desarrolla para el logro de la propia conservación y por añadidura de una vida más armónica; es decir, el deseo de abandonar la condición de guerra que es consecuencia necesaria de las pasiones naturales del hombre.

Ahora bien, este camino que hemos abordado sobre el Estado corresponde a categorías del pensamiento filosófico de la teoría del Estado, cuyos conceptos también son nutridos por pensadores de variadas disciplinas, además de la Ciencia Política, como Derecho, Historia, Economía, etcétera. Pero para entender la coyuntura estructural de una categoría de Estado, además del pensamiento filosófico, tendríamos que remitirnos a diversos elementos que lo componen, discursos en diversos ámbitos como el pedagógico, laboral, burocrático, ideológico, económico o jurídico, entre otros, y para eso tendríamos que acudir a fuentes históricas con una perspectiva historiográfica y hermenéutica, para comprobar que los indicios 
sean verificables y entender su contexto, así mismo podríamos utilizar diversas herramientas metodológicas para abordar la genealogía del Estado Moderno, para precisar más, entender y explicar la genealogía de una determinada categoría del Estado en su particularidad, por ejemplo, para abordar El Estado liberal incipiente de Inglaterra o en su modelo benefactor de una coyuntura histórica, tendríamos que remitirnos a su contexto a través de fuentes históricas y contextuales.

Sin embargo, existen elementos permanentes que nos parecen genéricos del Estado Moderno y son los que primordialmente nos interesan, precisamente la teoría del Estado es básica para la ideología de un Estado, el aparato jurídico, que si bien varía de un Estado a otro, está provisto de constantes en su aplicación y jurisprudencia adaptada que aún arbitran de un gobierno a otro, de igual manera, las políticas públicas remiten a contextos de modelos económicos que intervienen paradigmáticamente como mecanismos de biopoder en la gobernanza de diversas latitudes poblacionales del planeta.

Entonces lo que abordaremos en este texto, para hablar del Estado Moderno, será, en concreto, de la Política Criminal como biopolítica de la cuestión criminal, desde el análisis del discurso histórico filosófico de algunos conceptos y teorías de pensadores que han trascendido en el argumento técnico-jurídico del sistema penitenciario. Abordaremos las estructuras técnicas, los elementos reguladores o dispositivos de seguridad, que conducen a la conducta de la población en función del crimen y que han perdurado en la demagogia del discurso penitenciario desde su origen capitalista. Se abordará el modelo punitivo de la modernidad que obedece a la privación de la libertad llamado cárcel,y como este es un emporio de segregación social y de racismo, que a su vez, está ligado a un mercado del blindaje o industria de la seguridad. 
2. Derecho Penal como una de las instancias de la BIOPOLÍTICA

A partir de que comienzan a delinearse las fronteras entre los Estados soberanos en Europa, surgen estrategias de control para preservar las divisiones políticas, lo que aquí denominamos tecnologías, para la gobernabilidad de la población, que van desde políticas en cuestión migratoria, asimilación o exclusión de las diásporas, o, medidas de natalidad en pro o en contra de la sobrepoblación, todoo depende de cómo se mire la cuestión poblacional en las incipientes urbes.

Por ejemplo, Francisco Vázquez argumenta en su obra, La invención del racismo, Nacimiento de la biopolítica en España, 1600- 1940, que en España, la autoridad en turno, gobernaba bajo un regímen jurídico filosófico en ejercicio de la soberanía, legitimando su racionalidad bajo cuestiones utilitarias de gobernanza poblacional desde determinadas teorías afines a sus intereses soberanos. Ya fuesen religiosos o laicos los argumentos teóricos, fungirían como mediadores estratégicos para identificar, clasificar y eliminar los elementos defectuosos de la población que atentaban contra la perpetuidad del pacto social en un sistema de orden y progreso. ${ }^{19}$

Se mira al orden como la capacidad productiva y al progreso como esa capacidad que genera y garantiza la abundancia. Así, la tecnología en materia de salubridad y seguridad serán los mecanismos por excelencia de conservación y certeza ante la incertidumbre de conservación sanitaria o de seguridad poblacional, en los nacientes Estados soberanos. En este sentido, según Francisco Vázquez, las corrientes filosóficas, van categorizando lo nocivo y el Derecho lo legítima contribuyendo a la certeza de garantizar la soberanía. Entonces las técnicas de seguridad consistían en lineamientos jurídicos que apelaban a la sanción de conductas inconvenientes a

19 Cfr., Francisco Vázquez García, op. cit., nota 8. 
la soberanía, a su expulsión o contención de sectores o minorías considerados peligrosos o nocivos del Estado; pero también se delineaban estrategias de asimilación de etnias o sectores poblacionales nombrándolos ciudadanos, a estos últimos se les encausaba a ciertas conductas utilitarias en diversos ámbitos de la vida cotidiana como lo disponían políticas encaminadas a la reducción o promoción de la natalidad, eso dependía de la racionalidad gubernamental.

El proceso de desacralización de la pobreza, en el curso del cual el indigente deja de ser visto como encarnación simbólica de Cristo e instrumento para el ejercicio de la virtud, corre paralelo a la emergencia de una ética del trabajo que significa la labor estigmatizando el viejo otium de filiación aristotélica y renegando de las bondades secularmente asociadas a la vida contemplativa.

La expresión social e institucional de este cambio, verificado en el curso de las reformas protestante y católico, fue una política empeñada en el control de la mendicidad y eventualmente en el encierro correccional de los pobres. Este acontecimiento ha sido explicado a la luz de la historia social y económica, poniéndolo en relación con la afluencia masiva de pobres que, desde finales del Medioevo, inundaban periódicamente las ciudades de Europa occidental. Se ha dado cuenta del fenómeno conectándolo con las transformaciones estructurales que acompañan a la expansión del capitalismo mercantil y en la Edad Moderna, el crecimiento urbano, los ciclos demográficos y las crisis de subsistencia vinculadas a los virajes de la coyuntura. ${ }^{20}$

En este sentido dos elementos (entre muchos otros, como el religioso, filosófico, económico, migratorio, laboral, alimenticio, sexual, educativo, sanitario, etcétera) que incursionaron en el discurso demagógico de la biopolítica fueron el contrato social y el Derecho, lo cual detonó, en gran medida, la legitimidad al Derecho de castigar del gobernante de donde se derivan los principios generales de la Filosofía Clásica Penal Liberal. Así tenemos a César Beccaria con

20 Ibidem, p. 55. 
su libro De los delitos y de las penas ${ }^{21}$ de 1764 ; se dice que fue el primero en formular los principios del Derecho Penal y de la Criminología clásicos, basándose en las teorías de contrato social, revolucionando el ámbito político y jurídico al establecer las pautas que regirían al Derecho Clásico.

Debe agregarse a este contexto los contenidos de la declaración francesa de los Derechos del Hombre y del Ciudadano que reafirman los principios de legalidad y de procedimiento judicial, artículos 7 y 8 , el de separación de poderes artículo 16, entre otros retomados para el derecho público de muchos países, lo que permite la intervención gubernamental para regular diversos ámbitos sociales bajo pretexto de resguardar lasoberanía.

Por su parte el jurista Francesco Carrara, en su obra Programa de Derecho criminal de 1859, desarrolló una elaboración cuidadosa de todo el sistema penal general, la mejor doctrina del momento, con el primer estudio metódico de los delitos en particular. Para él la norma siempre es buena e imparcial, mientras el hombre es malvado por naturaleza, pues está de acuerdo con el postulado de Hobbes con respecto al contrato social. ${ }^{22}$

En este sentido, la verdad jurídica permite una de los eslabones más poderosos y prioritarios de la administración de la cuestión criminal, si bien es cierto se apoya en otras disciplinas, su papel en el proceso jurídico es de gran envergadura, como los es todo el aparato judicial, para construir el concepto y sujeto de delito en pro de la soberanía por su argumento racional. ${ }^{23}$

21 Cfr., C. Beccaria, De los delitos y de las penas, Madrid, Alianza Editorial, 1982.

22 Cfr., Francesco Carrara, Programa del Derecho Criminal, parte general, vol. I y II, Bogotá-Buenos Aires, Temis- Depalma, 1986.

23 Cfr., Michel Focault, Obrar mal, decir la verdad. La función de la confesión de la justicia, trad. Horacio Pons, Argentina, s. e. 2014. 
3. Tecnologías del castigo e industria de la cuestión CRIMINAL

En este contexto naciente del Estado Moderno que apela a la soberanía, la industria incipiente generó transiciones en las colectividades, conflicto, desorden social, hacinamiento en las ciudades, que algunos científicos abordaron como lo realizó Tomas Malthus, quien plantea en su teoría que la población puede crecer de manera geométrica mientras que el alimento se cultiva de manera lineal (para esa época), su concepto de población como excedente (ahora denominado explosión demográfica) es entendido por el aparato estatal de gobierno como un aspecto negativo del progreso, pues, si hay un problema de no correspondencia entre la producción de alimento y la demanda de subsistencia de una población, se debe intervenir con mecanismos de regulación con miras a prever la correspondencia. Éste es uno de los argumentos que contribuyeron a elevar a la vagancia y la mendicidad a la categoría de delitos pues la responsabilidad de proveer el alimento depende del individuo. Éste tiene que funcionar como consumidor activo que se hace cargo de la gestión de su alimentación por que ha adquirido la libertad de responsabilidad para vender su fuerza de trabajo y así proveerse de lo necesario para subsistir. Si la idea del progreso, aunada al pacto social, otorga la libertad al individuo para ser libre por garantizarle la existencia o perpetuidad de la vida, es el individuo quien decide ser responsable de vincularse al aparato productivo o estar en contra del pacto social al ser indigente.

La pobreza se relaciona a partir de entonces como una de los mayores frenos del progreso relacionándola a la irresponsabilidad del individuo, no de la sociedad, no del modelo de gobierno correspondiente al modelo económico capitalista. Es en este contexto, la indigencia comienza a asociarse con la cuestión de sanidad. Al tomarse la mendicidad, el desempleo o la protesta social como una patología social, la estrategia de gobernabilidad ante esta variante 
de riesgo anómala asume la gestión gubernativa como gestión de limpieza social hacia las zonas de riesgo o márgenes poblacionales criminógenos.

En este sentido podemos citar la obra de Anthony M. Platt: Los "salvadores del niño" o la invención de la delincuencia, donde se demuestra, cómo, las políticas gubernamentales se encaminan a la gestión del riesgo del desorden social devenido de la inconformidad de los grupos desocupados, legitimando esta estrategia o racionalizándola desde un marco jurídico institucional que conduce las conductas desde dos mecanismos de regulación, cuya invención, según el autor, es paralela: la beneficencia laica o asistencia social (diferente de la caridad religiosa previa a este modelo) y la invención de la delincuencia gestionadas por las élites.

Las reformas pro salvación del niño eran parte de un movimiento mucho mayor para reajustar las instituciones de modo que satisficieran los requerimientos del sistema emergente del capitalismo corporado. Desde el tumulto de Haymarket (1886), los centros de actividad industrial han sido afectados continuamente por huelgas, interrupciones violentas y muchos fracasos y fluctuaciones en los negocios. Movimientos activistas como el Partido Socialista y el de los trabajadores Industriales del Mundo, representaban las demandas de los trabajadores de que se efectuara un cambio fundamental en las condiciones sociales y económicas. Al salir el país de las depresiones y la violencia que se produjeron en la industria a fines del siglos pasado, los reformadores de la sociedad desencadenaron un movimiento para salvar y regular el capitalismo mediante la formación de una nueva economía política, destinada por una parte a estabilizar la producción y el planteamiento fiscal y por la otra cooptar la surgente oleada de militancia popular. ${ }^{24}$

De manera paralela, se desarrollaron diversos mecanismos utilitaristas. La coyuntura histórica propició una sería de técnicas y

24 Anthony Platt, Los "salvadores del niño" o la invención de la delincuencia, $4^{\mathrm{a}}$ ed. trad. Félix Blanco, México, Siglo XXI,2001, p. 20. 
teorías científicas en torno a la cuestión criminal y la seguridad del delito. Desde el ámbito arquitectónico se desarrolló el modelo celular consistente en el aislamiento por celdas como principio de control sobre el recluso.

Las primeras prisiones celulares se desarrollaron en los Estados Unidos, poco después de su independencia de Inglaterra. Su promotor fue el jefe cuáquero William Penn, que por sus principios religiosos, había estado preso en condiciones lamentables. Su ideología severa lo llevó al diseño y construcción de la colonia Pennssylvania entre 1790 y 1792.

Así mismo se propició la creación del panóptico como modelo del espacio de contención para prevención el riesgo garantizado por la vigilancia permanente de un vigía desde un punto estratégico sin ser visto por los reclusos. Fue B. Jeremy Bentham (1748- 1832) quien ideó el Panóptico, teórico del Derecho Penal Liberal, fue un pensador utilitarista pragmático, tuvo un interés particular por el disciplinamiento de las clases marginales, al ser miembro de la élite del momento. ${ }^{25}$

La antropotecnia también funge como dispositivo de seguridad para detectar perfiles de riesgo, así la idea de extirpar, eliminar o curar viene de la medicina para controlar o prevenir lo potencialmente nocivo. En el ámbito penitenciario fue Lombroso (1835-1909), fisiólogo de formación, quien con su teoría contribuyó al arraigo de la noción de extirpación de lo criminal como cura social. Su teoría influyó en la parte utilitarista de la criminología con su libro El hombre delincuente, donde desglosa una serie de categorías como originarias de la personalidad delictiva, para él, el perfil potencialmente criminal, obedecía al hombre involucionado denominado por él primitivo ( nombró primitivos a quienes portaban anomalías físicas degenerativas, estigmas o cuya fisionomía

\footnotetext{
2008 .

25 Cfr., Alicia González y Augusto Sánchez, Criminología, 2a ed. México, Porrúa,
} 
no correspondía al hombre promedio de ascendencia europeo). Es pionero, de la hipótesis biológica, de que la violencia obedece a una causa originaria en la fisiología humana hereditaria (genética) y por anomalías físicas. ${ }^{26}$ Aunque sus postulados han sido severamente criticados y se le nombra a su teoría seudociencia, por su falta de rigurosidad científica, sus postulados han sido útiles en la biopolítica de limpieza social encaminada a la eliminación de minorías y en la elaboración del perfiles criminales de procesos judiciales de muchas naciones, como fue el caso nazi encaminada a la eliminación de judíos y otros grupos, o en México cuando se criminalizan los grupos marginados o indígenas. ${ }^{27}$

Los aportes de Lombroso se enfocan al estudio de la fisonomía junto a postulados evolucionistas y un método positivista (conocimiento positivo por la caracterización de un método experimental que supone un objeto de estudio observable) sobre el campo jurídico. Él se ocuparía de la observación, de la medición, del cálculo a partir del diseño y aplicación de herramientas dando la pauta a la ciencia encargada de determinar las causas del comportamiento delictivo, la criminología. El delito ya no era explicado como un desliz del sujeto racional y libre, producto de un descuido intencional de la norma, sino a partir de ciertos rasgos propios del individuo que lo había cometido. Esos rasgos eran, precisamente, biológicos. El delincuente, para Lombroso, presentaba atributos morfológicos que lo hacían diferente a los otros individuos, mandíbulas muy pronunciadas, orejas sobresalientes o cráneos de proporciones inusitadas.

Las primeras formulaciones de Lombroso fueron muy discutidas en su momento. Enrico Ferri, además de ser su discípulo, es uno de sus críticos más importantes, pues considera a la teoría de su maestro como reduccionista que sólo ubica la degeneración humana,

26 Cfr., Josefina Álvarez y Augusto Sánchez, Antología de criminología 2a ed., México, UNAM-ENEP- Acatlán, 2003.

27 Cfr., Beatriz Urías Horcasitas, Historias del racismo, México, Tusquets, 2007. 
y no va más allá, así que reformula el método y la disciplina que denominará Sociología criminal.

Según Ferri, en su obra, retomó el método materialista histórico, mezclado con un positivismo biológico evolutivo que apela a las condiciones económicas de cada grupo social con sus fases evolutivas históricas, más sentimientos morales, más sus ideas políticas y jurídicas grupales, junto con factores biológicos y de energía de raza, más la constitución psico-física de los individuos y elementos cuantitativos derivados de análisis estadísticos. Termina por definir al delito, como cualquier otra acción humana, como un fenómeno de origen complejo, biológico y físico-social, con modalidades y grados diferentes según las circunstancias diversas de personas y cosas, de tiempo y lugar. ${ }^{28}$

La novedad de de la sociología criminal radica en la importancia del medio y su influencia en la conducta criminal. El análisis de las causas contextuales de la criminalidad se traduce inmediatamente en el diseño de medidas tendientes a la transformación del medio y a la creación de instituciones y legislaciones que atiendan a esas condiciones externas a los individuos. Eldiseño de los instrumentos ligados con la transformación del medio es uno de los temas privilegiados de la Sociología criminal para Ferri, quien llega a sugerir que la reforma del medio podría ocasionar la cura de ciertos males sociales y peligrosos.

La sociología criminal ocupa el estadio superior del desarrollo de las ciencias sociales, según Ferri, porque está encargada de conocer las causas de la criminalidad, preverla y tratarla. Está en sus manos el análisis de los medios preventivos más convenientes para dicho tratamiento, pretendiendo, para esta disciplina, el protagonismo direccional en las políticas e instituciones preventivas y penales. Según Ferri, cómo sociólogo criminal el científico investiga y explica, como criminalista sociólogo interviene.

28 Cfr., Enrico Ferri, Sociología criminal, Madrid, centro editorial de Góngora, 1970. 
No obstante, los sustitutos penales no son el único campo de acción del criminalista formado bajo el influjo de la sociología, le importa en general la reforma de todo el aparato de la justicia penal, ocupándose tanto de las prisiones y su funcionamiento como de la formación del personal de las mismas, encargado del trato con los delincuentes.

$\mathrm{Al}$ referirse a las prisiones, Ferri se detiene en definir el fin técnico que recae sobre ellas, que se suma a su fin jurídico de segregación del individuo peligroso. Ese fin técnico consiste en el desarrollo de hábitos de trabajo y de higiene que sólo puede realizarse efectivamente en ciertos modelos de prisiones adaptadas a caracteres de los tipos criminales y en absoluto en prisiones con sistema celular por cuestiones utilitarias. ${ }^{29}$

La tarea clínica de la sociología criminal consiste en el estudio, el control y la observación permanente de los criminales, pero también en el diseño de estrategias tendientes a remediar o paliar las disfuncionalidades y evitar los delitos, al transformar el medio para inhibir los factores que se juzgan propicios para la expresión de las inclinaciones antisociales. Es esta valoración de la ciencia como herramienta de prevención, la que marca definitivamente su oposición y su crítica al modeloclásico.

Es justamente con estos elementos discursivos que la gobernabilidad, en defensa de la soberanía, comienza la carrera industrial de la cuestión criminal hacía la producción ideológica en el ámbito científico y tecnológico como garantes de la seguridad frente al potencial riesgo construyendo la prevención del delito, bajo la segregación de la comunidad enmascarada por el panfleto de garantía de resguardo individual. Lo que lleva a ceder la libertad por seguridad.

29 Enrico Ferri, Defensas penales, México, Porrúa, 1990. 


\section{Conclusiones}

La posibilidad de eliminar el riesgo es un postulado ideológico que se ha desarrollado bajo el modelo científico y tecnológico de las ciencias exactas para predecir situaciones de potencial peligro. Así, la tecnología funge como herramienta interventora para el resguardo de la población en todas las esferas sociales desde que se desarrolla la demagogia de la racionalidad, como por ejemplo, la soberanía y la gobernabilidad que apelan al castigo como elemento racional de disuasión del delito bajo elementos técnicos científicos de un sistema penitenciario capitalista.

Se constituyen así elementos legitimadores de la racionalidad política permitiendo la creación de dispositivos de seguridad incrustados en una industria penitenciaria que justifica la etiqueta de delincuencia o crimen como potencial riesgo, cuyo control o prevención radica paralelamente en dos vertientes, por una parte, la categorización desde el método científico encaminado al tratamiento de la cuestión criminal junto con el proceso judicial del Estado como vectores deseñalamiento hacia los individuos que se les nomina como delincuentes.

Por otra parte, tenemos una carrera tecnológica, arquitectónica y policial que nutre su desarrollo y vanguardia de la situación o abordaje interventor del Estado y la ciencia hacia la cuestión criminal. Nos referimos a todos los elementos tecnológicos que se demandan y producen para la seguridad como cámaras, blindaje en casas o automóviles, dispositivos de bolsillo o armas, vigilancia privada, y un largo etcétera que se produce masivamente.

En este sentido podemos decir que delincuente funge como elemento imprescindible de la sociedad capitalista, es el chivo expiatorio de los conflictos sociales que devienen de la desigualdad social derivada de la enajenación y la plusvalía que se obtiene únicamente cuando unos cuantos ejercen dicha acumulación y obtención de la 
plusvalía, de la explotación laboral vista como mercancía paralelo a la producción del lumpen proletariado.

La función del lumpen proletariado (marginados, personas en situación de calle, prostitutas, sicarios, personas estigmatizadas por pertenecer a los grupos minoritarios) es generar riqueza cuando su potencial expansión como riesgo es latente desde la retórica soberana, lo que permite la plusvalía para quienes capitalizan los mecanismos de gobernabilidad de dicho sector. Entonces el lumpen proletariado son mercancías, en modelos de gobernabilidad policiales, que contribuyen a la producción de todo el aparato de ingeniería, tecnología y arquitectura y modelos científicos que promueven el concepto de crimen y conductas antisociales como capital humano del lumpen proletariado como potencial riesgo, dicho discurso permite generar todo un engranaje industrial que produce capital monetario.

Podemos decir que las políticas criminales, o lo que es lo mismo, la biopolítica de la cuestión criminal, no está enfocada a la readaptación sino a la gobernabilidad del crimen directamente proporcional a la demanda social, para promover mecanismos de resguardo frente al potencial delito del futuro mediato y por ello se utilizan proyecciones que se pretenden resolver con mecanismos tecnológicos como cámaras y no con mediaciones humanistas o de cohesión social.

Entonces el lumpen proletariado es la población de conejillos de indias que se utiliza en zonas marginales, zonas de tolerancia geográfica, pero principalmente en laboratorios llamados cárceles, fortificaciones que fueron adaptándose con la arquitectura, el derecho y la demagogia encaminada a la industria que se ha expandido y perfeccionado junto a la vanguardia tecnológica,en pro de la contención del riesgo futuro, en beneficio de la seguridad progresista de la población.

Es así como el término criminal o delincuente se ha convertido en un emblema o estereotipo de estigmatización, de racismo por 
excelencia, lo que es lo mismo, es la etiqueta más excluyente porque se dirige bajo una nominación racial de odio, de sospecha, de intolerancia, pero sobre todo porque refleja la concepción de miedo, inseguridad e incertidumbre de la población gobernada.

\section{Bibliografía}

Álvarez, Josefina y Sánchez Augusto, Antología de criminología $2^{a}$ ed., México, UNAM- ENEP-ACATLÁN, 2003.

Beccaria, C., De los delitos y de las penas, Madrid, Alianza Editorial, 1982.

Bodin, Jean, Los seis libros de la República, Madrid, Tecnos, 2006.

Carrara, Francesco, Programa del Derecho Criminal, parte general, vol. I y II, Bogotá- Buenos Aires, Temis- Depalma, 1986.

Clastres, Pierre, Arqueología de la violencia: la guerra en las sociedades primitivas, $2^{a}$ ed., trad. Luciano Padilla López, México, FGE, 2009.

Comte, Augusto, La filosofía positiva, 6a ed., México, Porrúa, 2000.

Darwin, Charles, El origen de las especies, 6 6 ed., México, Porrúa, 1997.

Esposito, Roberto, Confines de lo político, Madrid, Trotta, 1996. Ferri, Enrico, Defensas penales, México, Porrúa, 1990.

—- Sociología criminal, Madrid, centro editorial de Góngora, 1970.

Focault, Michel, Obrar mal, decir la verdad. La función de la confesión de la justicia, trad. Horacio Pons, Argentina, 2014.

Geulen, Christian, Breve historia del racismo, trad. Elena Bombín Izquierdo y Jesús de la Hera Martínez, Madrid, Alianza, 2007.

González, Alicia y Sánchez Augusto, Criminología, 2a ed. México, Porrúa, 2008.

Hobbes, Tomas, Leviatan, $2^{a}$ ed., trad. Ana Stellino, México, Gernika, 2000, t. I, p. 160. Platt, Anthony, Los "salvadores del niño" o la invención de la delincuencia, $4^{\mathrm{a}}$ ed., trad.

Félix Blanco, México, Siglo XXI, 2001.

Urías Horcasitas, Beatriz, Historias del racismo, México, Tiempo Dememoria Tusquets, 2007. 
Todorov, Tzvetan, El miedo a los bárbaros, trad., Noemí Sobregués, México: Círculo de lectores, 2013.

Vázquez García, Francisco, La invención del racismo. Nacimiento de la biopolítica en España, 1600-1940, Madrid, Akal, 2009.

Weber, Max., Economía y sociedad, México, $17^{\mathrm{a}}$ ed., trad. Medina Echavarría, José et al., FCE,2008. 